and Drug Administration." We also said, "Highdose interleukin-2 induces responses in 21 percent of patients, as compared with only 13 percent of patients who receive low-dose interleukin-2."2 We could have cited the McDermott study as well.

Herbert T. Cohen, M.D.

Boston University School of Medicine Boston, MA 02118

htcohen@bu.edu
Francis J. McGovern, M.D.

Massachusetts General Hospital

Boston, MA 02114

1. Atkins MB, Avigan DE, Bukowski RM, et al. Innovations and challenges in renal cancer: consensus statement from the first international conference. Clin Cancer Res 2004;10:6277S6281S.

2. Yang JC, Sherry RM, Steinberg SM, et al. Randomized study of high-dose and low-dose interleukin-2 in patients with metastatic renal cancer. J Clin Oncol 2003;21:3127-32.

\title{
Traumatic Cranial Nerve Palsy
}

TO THE EDITOR: Baker and Cannon (Nov. 3 issue $)^{1}$ describe a patient with left-sided ptosis and mydriasis after cranial trauma. The computed tomographic scan in Panel C of the image shows a bone fragment posteromedial to the dorsum sellae, suggesting a fracture of the anterior part of the petrous bone, rather than a lesion of the sella turcica, which is located more medially and cranially and would not be visible on the slice presented. A fracture of the anterior petrous bone may affect the third cranial (oculomotor) nerve as well as the eighth (acoustic) nerve. This matches perfectly with the clinical symptoms presented - that is, mydriasis (parasympathetic portion of the third nerve) and ptosis (motor portion of the third nerve), together with tinnitus and vertigo (eighth nerve). The combination of these symptoms is improbable in a patient with a fracture of the sella turcica. A careful clinical examination including pupil reactions and ocular movements would have been extremely helpful to localize the traumatic lesion.

Johannes R.M. Cruysberg, M.D., Ph.D. Thomas Theelen, M.D., Ph.D.

Radboud University Nijmegen Medical Center

6525 EX Nijmegen, the Netherlands
1. Baker C, Cannon J. Traumatic cranial nerve palsy. N Engl J Med 2005;353:1955.

THE AUthors RePLY: Drs. Cruysberg and Theelen have raised some interesting points. Their disagreement with our description of the fracture may be related to a difference in terminology. In fact, the sella turcica is a fossa within the sphenoid bone, which is fractured in the image in the report. Perhaps it would have been better to describe the lesion as a complex fracture of the lateral aspect of the sphenoid bone. Our neuroradiologists do not agree that the image shows a fracture of the anterior petrous bone.

Finally, with regard to performing a careful clinical examination, we would point out that the patient was intubated and paralyzed on arrival at the trauma center. The appropriate examinations were performed when the patient stabilized and was extubated.

Christopher C. Baker, M.D.

Jeremy Cannon, M.D.

Beth Israel Deaconess Medical Center Boston, MA 02215

\section{Case 36-2005: A Woman with Seizure, Disturbed Gait, and Altered Mental Status}

TO THE EDITOR: In the discussion of the clinical like episodes. Although no randomized trial of syndromes of mitochondrial encephalomyopathy, L-arginine therapy for the MELAS syndrome has lactic acidosis, and stroke-like episodes (the MELAS been performed, observational data support its syndrome), Dickerson et al. (Nov. 24 issue) ${ }^{1}$ do not use, particularly in the acute phase of the disormention L-arginine therapy. This option should be der. ${ }^{2,3}$ Improvement has been reported in strokeconsidered in the treatment of patients with stroke- like symptoms within 24 hours after the use of 